\title{
POR UMA POLÍTICA AMBIENTAL ETNOCONSERVACIONISTA NA AMAZÔNIA
}

FOR AN ETHNOCONSERVATIONIST ENVIRONMENTAL POLICY IN THE AMAZON

\author{
Rennan Moura Martins ${ }^{1}$ \\ https://orcid.org/0000-0002-1786-0408 \\ http://lattes.cnpq.br/6114883651240308 \\ Marcelino Carneiro Guedes 2 \\ http://orcid.org/0000-0003-2702-5614 \\ http://lattes.cnpq.br/9005172978014230
}

Recebido em: 30 de maio de 2020.

Aprovado em: 15 de julho de 2020.

RESUMO: a globalização e desenvolvimento industrial trouxeram consigo, nos últimos dois séculos, degradação ambiental e extinção da biodiversidade em escala sem precedentes. A massificação sociocultural aliada aos respectivos modelos de produção agrícola baseados no agronegócio e monocultura impactaram os ecossistemas, reduzindo substancialmente a saúde ambiental e humana. Faz-se necessário, com urgência, enxergar a espécie humana como parte do ecossistema, integrada à biota circundante e dela dependente para se reproduzir física, social e culturalmente. É primordial, ainda, a reforma dos sistemas de produção e comercialização agrícola, de forma a lidar imediatamente com as externalidades socioambientais onde são produzidas. Os povos indígenas habitam a Amazônia há milênios e seus modos de vida podem ser relacionados com impactos intermediários na floresta, que impulsionam a biodiversidade. Observar e aprender a etnoecologia dos povos indígenas e comunidades tradicionais da Amazônia é fundamental para práticas verdadeiramente sustentáveis. É necessário, ainda, aprimorar a política ambiental para a Amazônia numa perspectiva etnoconservacionista.

\begin{abstract}
: globalization and industrial development have brought, in the last two centuries, environmental degradation and extinction of biodiversity on an unprecedented scale. Sociocultural massification combined with the respective models of agricultural production based on agribusiness and monoculture impacted ecosystems, substantially reducing environmental and human health. It is urgently necessary to see the human species as part of the ecosystem, integrated with the surrounding biota and dependent on it to reproduce physically, socially and
\end{abstract}

\footnotetext{
${ }^{1}$ Formado em Gestão Ambiental, indigenista e mestrando no Programa de Pós-Graduação em Biodiversidade Tropical da Universidade Federal do Amapá. E-mail: rennan.m.martins@gmail.com.

2 Pesquisador da Embrapa. Professor do Programa de Pós-Graduação em Biodiversidade Tropical da Universidade Federal do Amapá. Possui graduação em Engenharia Florestal pela Universidade Federal de Viçosa (1996), aperfeiçoamento no departamento de Solos da UFV (1997), mestrado em Ciências Florestais [Esalq] pela Universidade de São Paulo (2001) e doutorado em Recursos Florestais pela USP (2005). E-mail: marcelino.guedes@embrapa.br.
} 
culturally. It is also essential to reform agricultural production and marketing systems, in order to deal immediately with the socio-environmental externalities where they are produced. Indigenous peoples have inhabited the Amazon for millennia and their ways of life can be related to intermediate impacts on the forest, which boost biodiversity. Observing and learning the ethnoecology of indigenous peoples and traditional communities in the Amazon is fundamental to truly sustainable practices. It is also necessary to improve the environmental policy for the Amazon from an ethnoconservationist perspective.

Palavras-chave: Globalização; Degradação ambiental; Etnoecologias; Povos Indígenas; Biodiversidade.

\section{A GLOBALIZAÇÃO DOS IMPACTOS E DEGRADAÇÃO AMBIENTAL}

A ampliação do comércio e integração econômica internacional atingiu patamares que não possuem qualquer paralelo na história da humanidade. O homo sapiens organizado em torno de um sistema socioeconômico emergido a partir da Revolução Industrial (sécs. XVIII e XIX) ampliou exponencialmente a sua capacidade de alteração do ambiente, de forma que praticamente todo o espaço terrestre já sofreu impacto de antropização, direto ou indireto. A influência é tamanha que não se trata de exagero equiparar a espécie a uma força equivalente à da própria natureza, estando inaugurada, então, a era do Antropoceno (Roosevelt 2014).

Se por um lado a tecnologia massiva nos proporcionou alta produtividade e automação de processos antes dispendiosos de maior tempo e esforço, por outro, acumulam-se externalidades socioambientais resultantes da degradação e uso intenso dos recursos naturais. Neste contexto, não se pode deixar de citar as consequências ecológicas da demanda energética pelos combustíveis fósseis, que tem ocasionado mudanças climáticas de efeitos dramáticos sobre o ambiente e paisagens globais (Ceballos et al. 2015).

A globalização trouxe consigo a homogeneização de usos e costumes de povos que anteriormente possuíam as mais diversas culturas e sistemas produtivos (Maffi 2015), cuja base agrícola, extrativista e proteica adaptava-se aos ecossistemas locais (Tsing 2017). O modo de vida dos povos originários, como os indígenas que colonizaram a Amazônia, seguia no ritmo da natureza, produzindo no próprio local os recursos necessários à sua sobrevivência e reprodução familiar. O ambiente e a biodiversidade local eram a base do sistema de produção, e por isso eram conservados para manter a capacidade produtiva e o equilíbrio dinâmico dos ecossistemas.

Em tempos de pandemia, fica ainda mais evidente a importância desses sistemas de produção locais. Quando as fronteiras são fechadas e o isolamento passa a ser uma obrigação, a não dependência de outros países e locais externos torna-se estratégica para a sobrevivência das populações. Isso se dá também em nível do ecossistema, onde a auto sustentabilidade é dependente de insumos internos, da reciclagem de nutrientes e da biodiversidade local.

A expansão do modo de vida ocidental, que transpôs e impôs um modelo específico de produção baseado na monocultura e processamento industrial de alimentos, tem impactos ecossistêmicos crescentes. Esses impactos afetam a saúde ambiental e humana em escalas e ordens diversas as quais a Ciência tem procurado compreender e quantificar, em acelerada corrida contra o tempo.

Este artigo pretende, por meio de uma revisão bibliográfica, questionar certos pressupostos 
teóricos que se refletem na política ambiental vigente no tocante à relação da espécie humana com seu meio. A partir de uma visão da Ecologia Histórica, propõe uma política ambiental calcada na valorização do conhecimento dos povos indígenas da Amazônia, que habitam a floresta há milênios e com ela aprenderam a se relacionar de forma bastante diversa da sociedade nacional.

\section{CONSEQUÊNCIAS IMPREVISÍVEIS E APRENDIZADO ECOLÓGICO PELA DOR}

A transformação de praticamente toda a superfície terrestre em paisagem humana, sob a égide de um sistema socioeconômico dependente do crescimento contínuo, desencadeou uma marcha voraz de simplificação e degradação ambiental. As evidências científicas acumuladas indicam extinção de espécies em escala sem precedentes, nos últimos 200 anos. Sob estimativas conservadoras, Ceballos et al. (2015) chegaram à conclusão de que, no último século, a extinção de espécies vertebradas é 114 vezes maior quando comparada a períodos anteriores. Um trabalho recente em que colaboraram 455 pesquisadores de diversos países e coordenado pela $\mathrm{ONU}$, chamou a atenção do mundo ao afirmar que um milhão de espécies vegetais e animais estão ameaçadas de extinção e que o próximo evento de extinção em massa já estaria ocorrendo (IPBES, 2019).

Uma intervenção de tamanho porte não deixaria de vir sem preço. A degradação massiva de habitats e o contínuo avanço sobre os ecossistemas desencadearam a eclosão de zoonoses de alta potência letal sobre a espécie humana, como o Ebola, e mais recentemente, a Covid19. A transmissão viral inter-espécies é altamente favorecida pela degradação de habitats (Bloomfield et al. 2020; Keesing et al. 2010). A exploração comercial de espécies silvestres, principalmente mamíferos como os morcegos, primatas e outras adaptadas às paisagens humanas fez escalar o surgimento de infecções sobre o homo sapiens (Jonhson et al. 2020).

O restabelecimento da saúde ecossistêmica e, consequentemente, humana passa necessariamente pela revisão da forma como entendemos e dispomos dos recursos naturais. É preciso, aliás, encarar a natureza não como repositório de "recursos" destinados à confecção de mercadorias. Faz-se necessário, com urgência, encará-la enquanto intrincado e holístico sistema biológico o qual devemos entender, considerar e respeitar para então, intervir (Shah 2020).

\section{O LUGAR DA AMAZÔNIA NA CONTEMPORANEIDADE: UMA DIS- PUTA}

Alvo de estereótipos e idealizações, a Amazônia, denominada Hileia pelos primeiros naturalistas coloniais, foi tida como vazio demográfico. O paraíso verde ou inferno equatorial de enorme biodiversidade, era avesso à ocupação humana e de baixa capacidade produtiva em termos agriculturais. Uma paisagem apta apenas à caça, pesca e coleta de especiarias para exportação aos grandes centros de ocupação humana.

Superado o paradigma colonial, passou-se à concepção da Amazônia enquanto território a ser ocupado, integrado e domesticado sob os preceitos das demais regiões brasileiras. O governo brasileiro, principalmente, na década de 70 , incentivou e financiou grandes projetos na região, sob o bordão de que era preciso "integrar para não entregar". A floresta deveria dar lugar a empreendimentos do agronegócio, mineração e infraestrutura de maneira a reproduzir 
o modo de vida e geografia dos demais domínios morfoclimáticos brasileiros.

O avanço da Ciência e a potencialização dos dilemas ocasionados pela expansão desenfreada de um modelo de sociedade urbana e industrial indiferente às especificidades geo-biológicas regionais fez emergir a perspectiva da Amazônia enquanto repositório de biotecnologia. Nesse sentido, o bioma deveria ficar intocado e protegido da ocupação, e ser destinado à pesquisa e extração de medicamentos e soluções aos problemas humanos. Um espaço a ser preservado da presença humana, necessariamente deletéria às demais formas de vida.

Atualmente, sabe-se que a Amazônia foi e é ocupada milenarmente por povos que aprenderam a conviver com a floresta e dela tirar seu sustento. A bacia Amazônica, quando da chegada dos europeus, estava amplamente habitada (Souza et al. 2020) por 4 a 5 milhões de pessoas (Clement 1999) pertencentes às mais diversas etnias, que praticam a agricultura desde, no mínimo, 5.000 anos atrás (Roosevelt 2014; Oliver 2008). A versão do vazio demográfico não passou de narrativa do vencedor da História.

No entanto, a disputa entre salvar o "pulmão do mundo" ou transformá-lo em ativo financeiro (mediante a modificação do uso do solo para instalação de pastagens e monoculturas, ou pela exploração mineral) permanece. As diferenças entre as visões preservacionistas e utilitaristas se acirraram desde a última crise econômica global, que eclodiu em 2008, cujos efeitos se desdobram e foram intensificados com a atual situação política no Brasil e na Amazônia. Se é verdade que conseguiu-se paralisar o desmatamento por algum breve período, também procede o fato de que voltou-se a avançar com voracidade sobre a floresta. Abril de 2020 foi testemunha da maior devastação em área de floresta amazônica desde 2008, segundo os dados do Sistema de Alerta de Desmatamento operacionalizado pelo Instituto do Homem e Meio Ambiente da Amazônia (Imazon).

A recente aceleração do desmatamento e queimadas na Amazônia, foi decisiva para que o Brasil aumentasse suas taxas de emissão de gases do efeito estufa, enquanto na maior parte do mundo, as emissões foram reduzidas pela diminuição nas atividades e circulação de pessoas. Os desmatadores e incendiários, sentindo-se autorizados pelo contexto de crise sanitária e política, cada vez mais avançam sobre a floresta, que já derrubada em mais de $20 \%$ da Amazônia. Aproxima-se o ponto de não retorno, no qual o desmatamento e degradação de 40\% do bioma amazônico representará a impossibilidade de regeneração da floresta (Nobre e Borma 2009), a aceleração da savanização, de consequências dramáticas para a dinâmica climática brasileira e mundial. Qual será o caminho a ser seguido?

\section{O POSITIVismo, A POLÍtica AMBIENTAL DE COMANDO E CON- TROLE E OS LIMITES DO MODELO}

Surgida em meados do século XIX, a Ecologia cresceu e se consolidou apenas a partir da metade do século seguinte, a reboque da emergência de sérias questões ambientais decorrentes do impacto humano sobre o meio ambiente. Sendo fruto de um determinado momento histórico, sua perspectiva foi e é produzida a partir de concepções teórico-filosóficas específicas, com suas potencialidades e limitações.

Baseada no conceito do equilíbrio e colocando o ser humano enquanto espécie apartada do sistema biológico, a Ecologia se desenvolveu sob o pressuposto de que a presença do homo sapiens é necessariamente prejudicial às demais espécies, ocasionando extinção e perda de biodiversidade. Tal perspectiva, produz, por exemplo, um curioso estudo (Peres et al. 2010) 
que dedica um capítulo inteiro a refutar o programa de pesquisa da Ecologia Histórica, sem, no entanto, abordar o impacto das populações indígenas sobre a paisagem.

A política ambiental brasileira enquanto decisões institucionais (baseadas no conhecimento técnico disponível, dentre outros fatores) de entidades estatais reflete também esta perspectiva. Inicialmente fragmentada em ministérios como o de Minas e Energia e da Agricultura (Moura 2016), adquiriu protagonismo e se tornou integrada apenas na década de 80, sob a forma da Lei $\mathrm{n}^{\circ} 6.938 / 81$, vigente até a atualidade.

Tal política é assentada, principalmente, na criação de áreas protegidas e em medidas de comando e controle, tendo a agência estatal (Ibama), e posteriormente também o ICMBio, o dever de cumprir e fazer cumprir as normas por meio de seus agentes fiscalizadores. Ocorre que, considerando a expansão agropecuária convencional, a pressão política e econômica que a acompanha, e os escassos recursos destinados à execução da política ambiental tal como é, se esbarra em severos limites à efetividade dessa política. Isso se reflete, principalmente, no na garantia de proteção integral e uso apenas indireto das 777 (MMA 2020) unidades de conservação dessa categoria. No caso da Amazônia, a imensidão da área, as dificuldades de acesso e a intrincada rede de drenagem tornam ainda mais difícil a missão da fiscalização.

A prática conservacionista (ou melhor, preservacionista) baseada na ausência de moradores e no impedimento do uso direto dos recursos, acaba por favorecer a exploração econômica e ilegal destas áreas. Como a fiscalização não dá conta de controlar toda a área e não há pessoas interessadas em manejar os recursos da floresta em pé, essas áreas acabam sendo ocupadas de forma totalmente insustentável para atividades agropecuárias, madeireiras, de garimpo e grilagem.

O fracasso da tentativa de retirar os humanos da natureza, a visão do homem enquanto espécie superior, apartada das demais, que utiliza do meio ambiente como mero repositório de recursos a ser transformados em ativos financeiros (Tsing 2017), nos trouxe até a dramática situação contemporânea. Urgente se faz a necessidade de nos encarar, e o sistema socioeconômico como um todo, enquanto entidades integradas à natureza. Nessa visão, do ser humano como um elemento qualquer do ecossistema, aumentam as responsabilidades de lidar com as externalidades de forma imediata, reduzindo ao máximo os impactos onde estes são produzidos. Isso, no intuito de garantir a saúde ecossistêmica e humana por consequência, pois, nesse caso, a destruição dos sistemas naturais pelas atividades humanas insustentáveis, é muito mais que um simples tiro no próprio pé.

\section{POVOS INDÍGENAS, COMUNIDADES TRADICIONAIS E SEUS SISTE- MAS DE IMPACTO INTERMEDIÁRIO}

São diversas as formas de interação do homem com o ambiente. Uma das mais essenciais, a agricultura, existe há milênios. Nessa escala de tempo, o homo sapiens coexistiu e evoluiu por milhares de anos com outras espécies. No entanto, a taxa de extinção das espécies vem crescendo exponencialmente nos últimos tempos. A sexta onda de extinção em massa (Ceballos et al.2015) é promovida pelos humanos a partir de um sistema socioeconômico específico, existente há menos de 500 anos, que não resume a totalidade da espécie e sua história de relação com a biota circundante. A sétima onda, em curso, e que pode levar a extinção de um milhão de espécies em poucas décadas (IPBES, 2019), se contrapõe ainda mais aos milhares de anos que o homem interagiu com a natureza sem causar essa degradação. 
Um olhar atento, aliás, nota que os povos que viveram por milênios em um determinado lugar o fizeram se adaptando e convivendo em sistemas multiespécies (Tsing 2017; Maffi 2005). A assunção de que toda presença humana, em sua enorme sociodiversidade, é supressora da biodiversidade, carrega consigo uma teoria implícita sobre a natureza humana (Baleé 1993), desprovida de comprovação factual. Uma análise mais detalhada da ecologia histórica da Amazônia e de seus povos originários, mostrará que, pelo contrário, a presença humana pode ser promotora da biodiversidade.

Esses povos indígenas e comunidades tradicionais da Amazônia reproduzem, até a atualidade (Levis et al. 2017), práticas agroecológicas que refletem um profundo conhecimento da ecologia local, de forma que a intervenção produzida na paisagem se faz sem a ocorrência de degradação do ecossistema circundante. Suas técnicas agrícolas, de caça e coleta, de manejo agroecológico em sentido amplo, parecem exercer distúrbios intermediários sobre o meio, que podem favorecer a diversidade. Dentre as práticas de manejo agroecológico dos povos indígenas da Amazônia, destacam-se: (1) remoção de plantas não-úteis, (2) proteção de plantas úteis, (3) atração de animais dispersores, (4) dispersão de plantas úteis, (5) seleção de fenótipos, (6) manejo do fogo, (7) plantio de espécies úteis, e (8) enriquecimento do solo (Clements et al. 2020).

A hipótese do distúrbio intermediário (Connel 1978; Sheil e Burslem 2003) vem acumulando evidências nas últimas décadas. Segundo a teoria, distúrbios intermediários possuem atributos (intensidade, periodicidade, área atingida) os quais fazem conviver, no mesmo sistema, espécies arbóreas de diferentes estágios sucessionais e estratégias de reprodução e crescimento. Ecossistemas expostos a distúrbios pequenos tendem a ser dominados por espécies maduras, competitivas e especialistas, enquanto os que são afetados por alta perturbação são dominados pelas espécies oportunistas, pioneiras, colonizadoras. Distúrbios intermediários, portanto, seriam promotores da diversidade arbórea em nível de paisagem, por possibilitarem a coexistência de espécies e promoverem um mosaico florestal de espécies de estágios iniciais e tardios da sucessão florestal.

Pesquisas desenvolvidas na Guiana Francesa ${ }^{1},{ }^{2}$ e nas bacias dos rios Gurupi e Pindaré ${ }^{3}$, dentre outras, apresentam sólidas evidências de que os distúrbios intermediários, exercidos também pelo modo de vida dos povos indígenas sobre a paisagem, impulsionam a diversidade arbórea local e regional. Guitet et al. ${ }^{1}$ (2018) levantaram a composição arbórea (Diâmetro à Altura do Peito DAP $>17,5 \mathrm{~cm}$ ) de 33 parcelas de floresta madura, em transectos de $20 \mathrm{~m}$ por $3 \mathrm{~km}$, atentando-se para que nas parcelas houvesse representatividade em termos de geomorfologia, altitude e precipitação (altura a nível do mar de 0 a $830 \mathrm{~m}$; precipitação de 2.000 a $4.000 \mathrm{~mm}$ anuais). Realizados os testes estatísticos, verificou-se que os distúrbios intermediários respondem por significativa parte da diversidade das espécies arbóreas. Nos termos dos autores:

Regimes de distúrbio intermediário continuados por milênios possibilitaram a sobrevivência de espécies de madeira leve, que demandam considerável luz solar, o desenvolvimento de uma rica vegetação de sub-bosque e uma diversificada comunidade de espécies arbóreas especialistas, características de estágios sucessionais maduros. (Guitet et al. 2018)

Mais recentemente, Odonne et al. $^{2}$ (2019) compararam parcelas de floresta madura encontradas dentro e fora de sítios arqueológicos. Os resultados indicaram atributos como biomassa aérea, área basal e densidade arbórea significativamente diferentes entre as categorias. 
Constataram ainda que a presença de parcelas antropizadas junto a não antropizadas propiciava o aumento da diversidade arbórea beta, em nível de paisagem.

Nesse tema, não se pode deixar de citar as contribuições pioneiras de Balée ${ }^{3}$ (1993). Tendo realizado inventários florestais em áreas de capoeira antiga e de floresta madura indicadas pelos indígenas locais (etnias Ka’apor, Guajá, Tembé e Guajajara), em uma área total de 8 hectares, verificou também significativas diferenças dentre as categorias, atestadas a partir de parâmetros florestais e estatísticos. O autor estabeleceu concretas diferenças dentre florestas expostas ou não a influência antropogênica de longo prazo, a partir do manejo agroecológico dos povos locais, demonstrando que existe maior diversidade nas áreas manejadas, que ele chamou de "florestas culturais".

Em outra frente, os estudos da ciclagem do carbono (Walker et al. 2019) em Terras Indígenas (TI's) e Áreas Protegidas (incluídas nesta categoria as Unidades de Conservação brasileiras) também endossam a tese ora defendida. Levantados os dados de armazenamento e ciclagem do carbono dentre 2003 a 2016 em Terras Indígenas e Áreas Protegidas de toda a Amazônia continental, verificou-se que as TI's conservam o carbono de forma mais efetiva e em maiores quantidades que as Áreas Protegidas.

É razoável concluir, com os dados expostos, que o modo de vida dos povos indígenas da Amazônia é conservacionista e, no mínimo, mantenedor da elevada biodiversidade amazônica. Considerando ainda que, no Brasil as TI's representam cerca de 13\% do território nacional, os povos indígenas prestam inestimável serviço ambiental à toda sociedade envolvente.

\section{ETNOCONHECIMENTO E PERSPECTIVA HOLÍSTICA: SISTEMAS AGROSILVIPASTORIS LOCAIS}

Temos, portanto, dois desafios a se enfrentar no tocante ao modo de vida da sociedade globalizada. O primeiro é a herança positivista enraizada na cultura técnico-científica, que se traduz numa postura filosófico-política de colocação do ser humano enquanto espécie a parte e alheia ao ambiente que o circunda. O segundo, consequentemente, é um sistema de produção agrícola voltado à transformação da natureza em ativo financeiro (Tsing 2017), desconectado dos processos ecossistêmicos locais e produtor de sérias e continuadas externalidades socioambientais negativas.

O primeiro desafio, a superação do paradigma natureza versus cultura, requer a modificação da forma como nos colocamos e o tipo de intervenção que executamos na paisagem para atendimento de nossas necessidades. É urgente o entendimento da inserção do homo sapiens enquanto espécie situada em contextos ecológicos e paisagens com especificidades regionais e locais. Não é possível nem saudável seguir com a massificação e homogeneização sociobiocultural, traduzida em modos de vida iguais para ambientes e paisagens diversas. A consequência desta postura está colocada: a extinção em massa da biodiversidade e a crescente degradação ambiental que deteriora as condições de saúde da própria vida como um todo.

O segundo, um desdobramento do anterior, exige a completa reforma das atividades de produção e comercialização de insumos e alimentos. O agronegócio, com seu modelo monocultor, dependente de intensa mecanização, da fertilização artificial e controle de pragas e doenças com uso de pesticidas, propagou e propaga a degradação e declínio da saúde ambiental e humana. Esse modelo, que utiliza a produção em escala para baratear os custos e a organização da cadeia produtiva para facilitar a comercialização para áreas muito distantes, depende 
de um custo energético de transporte, que, muito contribui para emissão de gases do efeito estufa. Além disso, qualquer balanço que se faça, da emergia contida em um alimento, em comparação com aquela utilizada para sua produção e transporte nessas condições, claramente evidencia que esse modelo é menos sustentável do que outro, baseado na produção e consumo de alimentos em cada local, a partir da sua biodiversidade endógena. Reformar este modelo depende, por sua vez, da observação e aprendizado dos modos de vida dos povos que viveram e vivem há milênios em interação responsável e, de fato, sustentável com a paisagem que habitam.

Não se trata de primitivismo, mas de olhar para o passado e projetar o futuro de forma consequente, utilizando-se da alta tecnologia, sob um dos princípios da sustentabilidade que é viver e deixar viver o máximo de espécies possível. A agricultura dos povos indígenas e comunidades tradicionais envolve a floresta e dela depende ('Tsing 2017). Os processos produtivos devem se integrar à regeneração florestal.

\section{REFORMA DA POLÍTICA AMBIENTAL A PARTIR DO FOMENTO AO USO SUSTENTÁVEL E AÇÕES DE PROTEÇÃO TERRITORIAL INTE- GRADAS ÀS COMUNIDADES}

Decorre do exposto, a essencialidade de políticas públicas de firme incentivo à pesquisa, resgate e registro dos conhecimentos milenares dos povos indígenas e comunidades tradicionais. Da contribuição à sociobiodiversidade depende a real sustentabilidade. Na mesma linha, o intercâmbio de conhecimentos, contínuo dentre essas comunidades, tem o potencial de impulsionar e aperfeiçoar práticas de produção agrícola e gestão ambiental.

Propõe-se ainda o fortalecimento da governança das Terras Indígenas e Unidades de Conservação, por meio de políticas públicas estruturadas e de diálogo permanente junto às comunidades, atentando-se às questões de escala e objetivos divergentes entre as instituições públicas gestoras e as organizações comunitárias (Petty et al. 2014). Isso é importante, para conciliálos na forma de regulamentações específicas, decididas conjuntamente, seguindo os protocolos de consulta livre, prévia e informada.

Em concomitância, o fortalecimento dos projetos de fomento à produção sustentável, considerando-se as especificidades ecológicas e culturais, tem um papel central na necessária reforma da política ambiental para a Amazônia. Isso, aliado a ações de vigilância e monitoramento territorial executadas em associação entre as comunidades locais e instituições gestoras, deve ser o caminho para a construção de um novo modelo de política ambiental inclusiva, verdadeiramente sustentável e consciente da responsabilidade socioambiental ocasionada pelo alto poder da sociedade de intervenção no meio ambiente.

\section{REFERÊNCIAS}

BALÉE, William. Indigenous transformation of Amazonian forests: An example from Maranhão, Brazil. L’Homme, França. Tome 33 n¹26-128. La remontée de l'Amazone. pp. 231-254. Dezembro, 1993. Disponível em: https://doi.org/10.3406/hom.1993.369639. Acesso em: 10/05/2020.

BLOOMFIELD, Laura S. P. MCINTOSH, Tyler L. LAMBIN, Eric F. Habitat fragmentation, livelihood behaviors, and contact between people and nonhuman primates in Africa. 
Landscape Ecol, Estados Unidos da América. 35, 985-1000. Abril, 2020. Disponível em: https://doi.org/10.1007/s10980-020-00995-w. Acesso em: 09/05/2020.

CEBALLOS, Gerardo. EHRLICH, Paul. BARNOSKY, Anthony. GARCÍA, Andrés. PRINGLE, Robert. PALMER, Todd. Accelerated modern human-induced species losses: Entering the sixth mass extinction. Science Advances, Estados Unidos da América. Vol. 1, no. 5, e1400253. Junho, 2015. Disponível em: 10.1126/sciadv.1400253. Acesso em: 10/05/2020.

CLEMENTS, Charles R. LEVIS, Carolina. FRANCO-MORAES, Juliano. Domesticated Nature: The Culturally Constructed Niche of Humanity. In: BALDAUF, Cristina. Participatory Biodiversity Conservation. Suíça: Springer Nature Switzerland AG, 2020. p. 35-51.

CONNEL, J. H. Diversity in Tropical Rain Forests and Coral Reefs. Science, Estados Unidos da América, 199: 1302-1310. Março, 1978. Disponível em: http://www.jstor.org/stable/1745369. Acesso em: 26/05/2020.

GUITET, Stéphane. SABATIER, Daniel. BRUNAUX, Olivier. COUTERON, Pierre. DENIS, Thomas. FREYCON, Vincent. GONZALEZ, Sophie. HÉRAULT, Bruno. JAOUEN, Gaëlle.

INTERGOVERNMENTAL SCIENCE-POLICY PLATFORM ON BIODIVERSITY AND ECOSYSTEM SERVICES. Nature's Dangerous Decline 'Unprecedented'

Species Extinction Rates 'Accelerating'. Disponível em: https://ipbes.net/news/Media-Release-Global-Assessment. Acesso em 13/07/2020.

MOLINO, Jean-François. PÉLISSIER, Raphaël. RICHARD-HANSEN, Cécile. VINCENT, Grégoire. Disturbance regimes drive the diversity of regional floristic pools across Guianan rainforest landscapes. Sci Rep, Reino Unido. 8, 3872. Março, 2018. Disponível em: https://doi.org/10.1038/s41598-018-22209-9. Acesso em: 09/05/2020.

JOHNSON, Christine. HITCHENS, Peta. PANDIT, Pranav. RUSHMORE, Julie. EVANS, Tierra. YOUNG, Cristin. DOYLE, Megan. Global shifts in mammalian population trends reveal key predictors of virus spillover risk. Proc. R. Soc. B, Reino Unido. 287: 20192736. Março, 2020. Disponível em: http://dx.doi.org/10.1098/rspb.2019.2736. Acesso em: 10/05/2020.

KEESING, Felicia. BELDEN, Lisa. DASZAK, Peter. DOBSON, Andrew. HARVELL, C. Drew. HOLT, Robert. HUDSON, Peter. JOLLES, Anna. JONES, Kate. MITCHELL, Charles. MYERS, Samuel. BOGICH, Tiffany. OSTFELD, Richard. Impacts of biodiversity on the emergence and transmission of infectious diseases. Nature, Estados Unidos da América. 468, pages 647-652. Dezembro, 2010. Disponível em: doi:10.1038/nature09575. Acesso em: 24/05/2020.

LEVIS, Carolina. FLORES, Bernardo. MOREIRA, Priscila. LUIZE, Bruno. ALVES, Rubana. FRANCO-MORAES, Juliano. LINS, Juliana. KONINGS, Evelien. PEÑA-CLAROS. BONGERS, Frans. COSTA, Flavia. CLEMENT, Charles. How People Domesticated Amazonian Forests. Frontiers in Ecology and Evolution, Suíça. Volume 5, Pages 171. Janeiro, 2018. Disponível em:https://doi.org/10.3389/fevo.2017.00171. Acesso em: 29/05/2020.

MAFFI, Luisa. Linguistic, cultural, and biological diversity. Annual Review of Anthropology, Estados Unidos da América, Vol. 34:599-617. Outubro, 2005. Disponível em: https:/ /doi.org/10.1146/annurev.anthro.34.081804.120437. Acesso em: 09/05/2020. MOURA, Adriana. Trajetória da Política Ambiental Federal no Brasil. In: Governança ambiental no Brasil: Instituições, atores e políticas públicas. Brasil: Ipea, 2016. Disponível em: https://www.ipea.gov.br/portal/images/stories/PDFs/livros/livros/160719_governanca_ambiental.pdf. Acesso em: 24/05/2020. 
NOBRE, Carlos. BORMA, Laura. 'Tipping points' for the Amazon forest. Current Opinion in Environmental Sustainability, Holanda. Volume 1, Issue 1, Pages 28-36. Outubro, 2009. Disponível em: https://doi.org/10.1016/j.cosust.2009.07.003. Acesso em : 09/05/2020.

ODONNE, Guillaume. VAN DEN BEL, Martijn. BURST, Maxime. BRUNAUX, Olivier. BRUNO, Miléna. DAMBRINE, Etienne. DAVY, Damien. DESPREZ, Mathilde. ENGEL, Julien. FERRY, Bruno. FREYCON, Vincent. GRENAND, Pierre. JÉRÉMIE, Sylvie. MESTRE, Mickael. MOLINO, Jean-François. PETRONELLI, Pascal. Long-term influence of early human occupations on current forests of the Guiana Shield. Ecology, Estados Unidos da América. V 100, Issue 10, e02806. Junho, 2019. Disponível em: https://doi.org/10.1002/ecy.2806. Acesso em: 09/05/2020.

OLIVER, J.R. The Archaeology of Agriculture in Ancient Amazonia. H. Silverman e W. Isbell (orgs). In: The Handbook of South American Archaeology. Estados Unidos da América: Springer Nature, 2008. Disponível em: https://link.springer.com/book/10.1007/978-0-38774907-5. Acesso em: 21/05/2020.

PERES, Carlos. GARDNER, Toby, BARLOW, Jos. ZUANON, Jansen. MICHALSKI, Fernanda. LEES, Alexander. VIEIRA, Ima. MOREIRA, Fátima. FEELEY, Kenneth. Biodiversity conservation in human-modified Amazonian forest landscapes. Biological Conservation, Holanda. Volume 143, Issue 10, Pages 2314-2327. Outubro, 2010. Disponível em: https://doi.org/10.1016/j.biocon.2010.01.021. Acesso em: 09/05/2020.

PETTY, Aaron. ISENDAHL, Christian. BRENKERT-SMITH, Hannah. GOLDSTEIN, David. RHEMTULLA, Jeanine. RAHMAN, Syed. KUMASI, Tyhra. Applying historical ecology to natural resource management institutions: Lessons from two case studies of landscape fire management. Global Environmental Change, Holanda. 31, 1-10. Novembro, 2014. Disponível em: https://doi.org/10.1016/j.gloenvcha.2014.11.004. Acesso em: 09/05/2020.

ROOSEVELT, Anna. The Amazon and the Anthropocene: 13,000 Years of Human Influence in a Tropical Rainforest. Anthropocene, Holanda. Volume 4, Pages 69-87. Dezembro, 2013. Disponível em: https://doi.org/10.1016/j.ancene.2014.05.001. Acesso em : 09/05/2020.

SHAH, Sonia. Contra a pandemia, ecologia. Le Monde Diplomatique. São Paulo, 28 de fev. de 2020. Disponível em: https:// diplomatique.org.br/contra-a-pandemia-ecologia/. Acesso em: 10/05/2020. Janeiro, 2003. Disponível em: https://doi.org/10.1016/S0169-5347(02)00005-8. Acesso em: 26/05/2020.

SHEIL, David. BURSLEM, Robert. Disturbing hypotheses in tropical forests. Trends in Ecology \& Evolution, Estados Unidos da América. 18, 18-26.

SOUZA, Jonas. MATEOS, Jonas. MADELLA, Marco. Archaeological expansions in tropical South America during the late Holocene: Assessing the role of demic diffusion. PLoS ONE, Estados Unidos da América. 15(4):e0232367. Abril, 2020. Disponível em: https://doi.org/10.1371/journal.pone.0232367. Acesso em: 09/05/2020.

WALKER, Wayne. GORELIK, Seth. BACCINI, Alessandro. ARAGON-OSEJO, Jose Luis. JOSSE, Carmem. MEYER, Chris. MACEDO, Marcia. AUGUSTO, Cicero. RIOS, Sandra. KATAN, Tuntiak. SOUZA, Alana. CUELLAR, Saul. LLANOS, Andres. ZAGER, Irene. MIRABAL, Gregorio. SOLVIK, Kylen. FARINA, Mary. MOUTINHO, Paulo. SCHWARTZMAN, Stephan. The role of forest conversion, degradation, and disturbance in the carbon dynamics of Amazon indigenous territories and protected areas. Proceedings of the National Academy of Sciences of the United States of America, Estados Unidos da América. 117 (6) 3015-3025. Janeiro, 2020. Disponível em: https://doi.org/10.1073/pnas.1913321117. Acesso 
em: 09/05/2020.

TSING, ANNA. A Threat to Holocene Resurgence Is a Threat to Livability. In: BRIGHTMAN, Marc. LEWIS, Jerome (org.). The Anthropology of Sustainability. Estados Unidos da América: Springer Nature, 2017. Disponível em: https://link.springer.com/book/10. 1057/978-1-137-56636-2. Acesso em: 20/05/2020. 